\title{
Expansão de vagas na Educação Superior no Brasil: uma política de Estado, de governo ou do mercado?
}

\author{
Expansion of places in Higher Education in Brazil: a \\ state, a government or a market policy?
}

\section{La expansión de la educación superior en Brasil: una política de Estado, el gobierno o el mercado?}

\author{
Jacqueline Oliveira Lima Zago*
}

\begin{abstract}
Resumo: O objetivo deste artigo é contextualizar as políticas de expansão de vagas na Educação Superior empreendidas pelos últimos governos do Estado brasileiro no processo de Reforma da Educação Superior em um recorte temporal referente às duas últimas décadas do século passado e que continuam em pleno processo de implementação. Com esse propósito, será problematizado: quais foram os impactos dessas políticas para a Educação Superior? Quando e como historicamente se situam esses projetos nesse processo? O percurso metodológico utilizado propôs-se a analisar, à luz de teóricos dessa temática, se os números publicados pelo INEP no Censo da Educação Superior refletem o discurso de democratização do acesso a esse nível de ensino. Levou-se em consideração o atual momento da Educação Superior brasileira, a recente conjuntura político-econômica de economia mundializada, a redefinição do papel do Estado-Nação e sua relação com a sociedade civil, suas diferentes frentes de atuação e focos de interesse.
\end{abstract}

Palavras-chaves: Política Educacional. Educação Superior. Censo da Educação Superior.

\begin{abstract}
The purpose of this article is to contextualize the political expansion of places in Higher Education undertaken by the last governments of the Brazilian State in the Reform of Higher Education in a time frame referring to the last two decades of the last century and that is still in the process of implementation. With this goal, it will be questioned: what were the impacts of these policies on Higher Education? When and how are these projects historically situated in this process? The methodological approach aimed to analyze, based on this theoretical issue, if the data published by INEP in Higher Education Censo reflect the discourse of democratization of access to this level of education. We took into account the current Brazilian Higher Education, the recent political-economic context of globalized economy, the redefinition of the
\end{abstract}

\footnotetext{
* Pedagoga na Universidade Federal do Triângulo Mineiro. Mestre em Educação pela Universidade Federal de Uberlândia. E-mail: <jacquelinejolz@gmail.com>
} 
role of the nation state and its relationship with civil society, its different performance fronts and areas of interest.

Keywords: Education Policy. Higher Education. Higher Education Censo.

Resumen: El propósito de este artículo es contextualizar la expansión política de los lugares en la educación superior emprendida por los gobiernos anteriores del Estado brasileño en la Reforma de la Educación Superior en un marco de tiempo en referencia a las dos últimas décadas del siglo pasado y todavía en el proceso de implementación. Esta será interrogado: ¿cuáles fueron los impactos de estas políticas en la educación superior , y cuándo y cómo estos proyectos están situados históricamente en este proceso? El enfoque metodológico utilizado buscó analizar, a la luz de esta cuestión teórica , si las cifras publicadas por el INEP en el Censo de Educación Superior reflejan el discurso de la democratización del acceso a este nivel de educación. Nos tomamos la actual educación superior brasileña , el contexto político -económico actual de la economía globalizada , la redefinición del papel del Estado-nación y la nueva configuración de la sociedad civil capitalista y sus diversos frentes y temas de interés en cuenta.

Palabras clave: Política de la Educación. Educación Superior. Censo de Educación Superior.

\section{Introdução}

Quem trabalha na universidade pública - professores, estudantes, funcionários - têm consciência de que a instituição pertence ao Estado Democrático de Direito e deve obedecer às normas de convívio estabelecidas na Constituição politica. A universidade pública se define pelo seu âmbito estatal on nada significa. (ROMANO, 2006, p. 18).

O presente artigo pretende contextualizar as políticas de expansão de vagas na Educação Superior empreendidas pelos últimos governos do Estado brasileiro no processo de Reforma do Estado e da Educação em um recorte temporal referente às duas últimas décadas do século passado e à primeira década do século atual. Para isso, será problematizado: quais foram os impactos dessas reformas para a Educação Superior? Houve uma expansão efetivamente democrática de acesso à Educação Superior pública e estatal? Quais são os desafios encontrados pelas instituições para a implementação dessa proposta expansionista? A expansão de vagas do acesso à Educação Superior pública e estatal, nos moldes como se tem materializado, atende, de fato, a que interesses?

O percurso metodológico exigiu uma contextualização histórica desse processo, primeiramente analisando o contexto mais amplo de políticas sociais do Estado brasileiro e sua relação com a sociedade. Relação essa que, conforme 
apontam os estudos de pesquisadores dessa temática, se manteve em permanente conflito, ainda que de forma mais ou menos evidenciada, tendo em vista ora o afastamento ora a aproximação com determinados grupos de interesse. Tratar de um tema como esse é voltar-se para o universo das políticas públicas e sociais defendidas e implementadas por meio do aparelho estatal (SILVA JUNIOR, 2009, 2011; SGUISSARDI, 2009; SILVA JUNIOR; SGUISSARDI, 1999, 2000a, 2000b, 2000c, 2005, 2009, 2012; CHAUÍ, 1999a, 1999b, 2001, 2003a, 2003b; LIMA, K., 2007; LIMA; FREITAS, 2013; DOURADO; CATANI; OLIVEIRA, 2002, etc.).

Como ponto de partida, situamo-nos entre aqueles que entendem que todo o emaranhado no qual se definiram as políticas públicas atuais foram reflexos de opções tomadas pelos governos e seus legisladores aliados, em que o Estado Republicano foi reconfigurado no que tange à sua missão, princípios e valores. Para implantação dessa nova forma de gerir a administração pública, foi necessário desprezar vários preceitos da Constituição Federal via emendas, leis, decretos, medidas provisórias, entre outros instrumentos legais que instituíram significativas mudanças ${ }^{1}$. O poder executivo consolidou-se como o responsável pela regulação e pela supervisão dos bens públicos e não mais órgão que deveria garantir esses mesmos bens, antes compreendidos como direitos sociais constitucionais.

Assim sendo, a análise será construída levando-se em consideração o atual momento da Educação Superior brasileira, a conjuntura político-econômica atual de economia mundializada, a redefinição do papel do Estado-Nação e a nova configuração da sociedade civil capitalista e suas diferentes frentes de atuação e focos de interesse.

Os frutos do conúbio entre os poderes da República com os grupos financeiros internacionais foram evidenciados (ROMANO, 2006). Toda essa reconfiguração visaria única e exclusivamente atender à expectativa de fazer parte do comércio dos grandes centros e, para isso, seria preciso alinhar-se com as diretrizes de poderosas agências transnacionais que assim o exigiam. Agências estas cujo objetivo principal é a expansão do capital via nova organização do modo de produção, distribuição de mercadorias e apropriação de riquezas em todo o mundo (ANTUNES, 2000, 2005, 2011; FRANÇA, 2010; GENTILI, 1998; LIMA, I. R. S., 2006; NOVACK, 1988). A partir desse objetivo, a política econômica brasileira elegeu esse modelo para o seu desenvolvimento.

Para essa empreitada, seria necessário ampliar o nível de escolaridade da população como define a Teoria do Capital Humano defendida pelos novos

\footnotetext{
${ }^{1}$ Exemplo significativo foi a redefinição do direito à educação que na Constituição Federal de 88 é "direito de todos e dever do Estado e da família" e, na LDBEN de 96, inverte-se para "dever da família e do Estado".
} 
liberais. Essa passaria a ser condição imprescindível para o desenvolvimento do país, preparar mão de obra qualificada, torná-lo um mercado consumidor e ao mesmo tempo local de desejo para instalação de fábricas multinacionais (ANTUNES, 2011). A Educação Formal adequar-se-ia nas mais variadas formas e conteúdos em todos os seus níveis e modalidades, evidenciando as disputas pelos diferentes projetos de sociedade, via elementos que lhe dão sustentação.

Novas palavras de ordem emergem no meio educacional, impregnadas dos valores da nova gestão empresarial que visa, entre outros, aliviar a pressão exercida por aqueles-que-vivem-do-trabalho ${ }^{2}$, como nomeou Antunes (2005), imputando-lhe a responsabilidade de não ser empregável. Importante ressaltar que o status social que carrega a educação está baseado na crença de que ela seria o meio pelo qual os indivíduos sociais ingressariam no mundo do trabalho (ou mercado consumidor) e, consequentemente, teriam acesso à cidadania plena. Ampliar o mercado empresarial para setores antes organizados sob a lógica pública cria exigências e demandas para a sociedade de maneira geral e para as instituições, sobretudo as educacionais. Assim, garantir o acesso à educação torna-se uma poderosa estratégia a grupos que almejam o comando do executivo e/ou uma cadeira no legislativo.

Em tempos que as pesquisas científicas nem sempre expressam as necessidades da sociedade, interrogamos as políticas públicas que foram construídas bem como os objetivos expressados e seus desdobramentos. Examinaremos as medidas que incidem sobre a educação superior de modo a evidenciar como essas medidas interferem no funcionamento das instituições de ensino superior com especial destaque para as instituições federais de Educação Superior. O desenho institucional e organizacional proposto pelo governo federal e as medidas em curso no interior das universidades públicas exigem olhares e interpretações mais consistentes para entender os meandros das políticas educacionais implementadas sobre a batuta de diretrizes neoliberais.

Acreditamos que um dos motivos que concorreram para a manutenção dos atuais grupos majoritários no poder executivo, legislativo e mesmo judiciário, foi o discurso da democratização do acesso aos níveis superiores de educação como garantia e manutenção desse modelo de desenvolvimento econômico da nação ${ }^{3}$. No entanto, a partir dos dados disponibilizados, pretendemos contrapor os números da Educação Superior ao discurso de democratização do acesso a esse nível de ensino. No fôlego desse objetivo, observaremos se a proporcionalidade

\footnotetext{
${ }^{2}$ Termo utilizado por Ricardo Antunes (2000) para indicar a classe trabalhadora de maneira mais geral e não mais o trabalhador regido por contratos formais.

${ }^{3}$ Modelo este que insere no ideário social como única forma de viver em sociedade de maneira justa e equitativa.
} 
de matrículas entre as categorias administrativas pública (estatal) e privada estão menos antagônicas. Isso porque reconhecemos o lugar dado à educação formal para uma sociedade mais justa e democrática, mas salientamos que o acesso é só o primeiro passo.

\section{Enterrando a social democracia não vivida}

Depois de anos de instabilidade econômica e projetos mal sucedidos de controle da economia que desaguaram em graves crises financeiras, econômicas e políticas, a administração pública passa a ser questionada. Estamos em 1994 e o novo chefe do executivo ${ }^{4}$ deu início a um Programa ousado de ajuste na política econômica com o objetivo de controlar a hiperinflação do país: o Plano Real. A estratégia utilizada no plano seria a desindexação da economia ${ }^{5}$, acompanhada de um amplo processo de privatizações, equilíbrio fiscal, abertura econômica, contingenciamento de serviços públicos e políticas monetárias restritivas (ANTUNES, 2000, 2005, 2011; FRANÇA, 2010; GENTILI, 1998; LIMA, I. R. S., 2006; NOVACK, 1988).

O efeito imediato do Plano Real refletiu-se na capacidade de consumo da população, o que elegeu o então Ministro da Fazenda para a Presidência da República: Fernando Henrique Cardoso (FHC). O novo presidente deu seguimento à política econômica do Plano Real e com o apoio da sociedade civil inaugurou um projeto mais amplo de Reforma do Estado (BRESSER-PEREIRA, 2003).

O grande mérito de Fernando Henrique como homem político, ao contrário do que se passou com o presidente Sarney em 1985, foi entender que a sociedade brasileira estava farta da inflação crônica que a acompanhava fazia mais de quinze anos. Quando aceitou o convite para ser Ministro da Fazenda do cambaleante governo Itamar Franco, em 1993, ele já sabia o que iria fazer. Chamou imediatamente a equipe de Economistas da PUC para trabalhar consigo e apresentou à sociedade seu plano de estabilização. O sucesso imediato deu-lhe o cargo de presidente da República nas eleições de 1994. (BARROS, 2002, p. 108).

A Reforma do Estado tomou forma e conteúdo tanto do ponto de vista organizacional, ou seja, na esfera do governo, como também no ponto de vista político, sobretudo no aspecto cultural. Nesse projeto, FHC constituiu uma equipe de governo em que toda a energia voltar-se-ia para uma política fiscal e

\footnotetext{
${ }_{4}^{4}$ Após o impeachment do Presidente da República Fernando Collor de Melo assumiu interinamente o papel de chefe de Estado, em dezembro de 1992, o vice-presidente Itamar Franco, recém-partidário do PMDB.

${ }^{5}$ A proposta de desindexação de FHC começou pelos salários que passariam a ser fixados por meio da livre negociação coletiva.
} 
monetária que viabilizasse o seu projeto de desenvolvimento econômico que ficou conhecido como âncora cambial.

No governo de FHC, a Secretaria da Administração Federal (SAF) foi transformada em Ministério da Administração e Reforma do Estado (MARE) e, liderada pelo economista Bresser-Pereira ${ }^{6}$, inaugurou o Plano Diretor da Reforma do Aparelho do Estado (PDRAE). Para Bresser-Pereira (2001, p. 22-23), “[...] o Brasil tinha a oportunidade de participar desse grande movimento de reforma, e constituir-se no primeiro país em desenvolvimento a fazê-lo".

Com o apoio do Legislativo, foi aprovada a Emenda Constitucional da Reforma Administrativa n ${ }^{\circ}$ 19, de 4 de junho 1998. Dentre as modificações introduzidas por essa Emenda, lembramos a perda de estabilidade dos servidores públicos com avaliações Periódicas de desempenho, a instituição do Regime Jurídico Único, que padroniza a remuneração dos agentes públicos, e a instituição da gestão gerencial da administração pública.

Ao longo do processo de implantação do Plano, e mesmo em textos atuais, o próprio idealizador da reforma, Bresser Pereira, confessa não estar interessado em discutir com os novos liberais ou a velha guarda de esquerda sobre o grau de intervenção do Estado nas esferas pública, privada ou público-privada. $\mathrm{Na}$ concepção desse economista, essa discussão já estaria superada e o que estaria em pauta, nesse Plano, seria o consenso sobre a inviabilidade do Estado de Bem-estar Social e a falta de apoio para o Estado Mínimo 7 . Para ele, o foco do Plano seria a ação reguladora, corretora e estimuladora do Estado (BRESSERPEREIRA, 2001, 2003, 2012).

Conforme disposto no PDRAE, no núcleo estratégico do governo, a propriedade seria por definição estatal. Já, na esfera de produção de bens e serviços, a propriedade deveria ser privada, particularmente nos casos em que o mercado controla as empresas comerciais. Em relação aos serviços sociais e científicos, a propriedade deveria ser essencialmente pública não estatal.

"Propriedade pública", no sentido de que se deve dedicar ao interesse público, que deve ser de todos e para todos, que não visa ao lucro; "não estatal" porque não é parte do aparelho do Estado. [...] É mais confiável do que as empresas privadas porque, em áreas tão delicadas como a educação e a saúde, a busca do lucro é muito perigosa. É mais eficiente do que a de organizações estatais, porque pode dispensar dos controles burocráticos rígidos, na medida em que as atividades envolvidas são geralmente atividades competitivas, que

\footnotetext{
${ }^{6}$ Formado em Direito (USP), Mestre em Administração e Doutor em Economia (USP), Bresser-Pereira instituiu uma "classe" de intelectuais orgânicos que formularia a teoria estrutural da reforma da gestão pública.

${ }^{7}$ Também chamado de Estado Providência ou Welfare State, o Estado de Bem-estar Social teria surgido na Europa após a crise causada pela Segunda Guerra Mundial baseado no pensamento keinesianista de pleno emprego.
} 
podem ser controladas por resultados com relativa facilidade. (BRESSER-PEREIRA, 2001, p. 25).

Por outro lado, mas seguindo a mesma linha, FHC contou com a auspiciosa articulação da então primeira dama, Dona Ruth Cardoso, que colocou em prática o objetivo de indicar a responsabilização da sociedade civil para a oferta dos serviços não exclusivos do Estado, ou seja, boa parte dos chamados direitos sociais. Conforme tese de doutoramento de Ferrarezzi (2008), assessora de Dona Ruth, assim que ficou sabendo da vitória de FHC, a Primeira Dama delineou sua atuação na base do governo, de modo a aplicar o que foi objeto de estudo durante sua vida.

Assim como Bresser-Pereira, Ruth Cardoso expressaria sua confiança na democracia como única forma possível de justiça social. Foi ela quem criou e presidiu o Conselho da Comunidade Solidária no Governo Federal durante todo o governo de FHC, propondo uma ampla reforma do marco legal do terceiro setor ${ }^{8}$. Para Dona Ruth, esse órgão seria “[...] um novo instrumento de diálogo político e de promoção de parcerias entre Estado e sociedade para o enfrentamento da pobreza e da exclusão por intermédio de iniciativas inovadoras de desenvolvimento social" (FERRAREZI, 2008, p. 238).

O Conselho da Comunidade Solidária seria uma organização indutora de programas e projetos em parcerias, sem jamais confrontar-se com as atribuições do Estado, mas aproveitando os "recursos existentes na sociedade" (FERRAREZI, 2008, p. 238). Daí surge o conceito de organizações sociais, conforme posto no volume 2 dos Cadernos do MARE, os quais

[...] incluem no setor público não estatal autorizadas pelo Parlamento a receber dotação orçamentária como uma estratégia central do PDRAE com o propósito mais genérico de permitir e incentivar a "publicização", ou seja, a produção não lucrativa pela sociedade de bens ou serviços públicos não exclusivos de Estado. (BRASIL, 1997, p. 7).

Desde então, foram criadas mais de 290 mil Fundações privadas sem Fins Lucrativos conforme estudo apontado no Perfil das Fundações Privadas e Associações sem Fins Lucrativos em 2010. No início dos anos 90, o número de fundações privadas e associações sem fins lucrativos eram de 90 mil, das quais aproximadamente $30 \%$ eram de cunho religioso, atuando, especificamente, nos direitos sociais delegados pela constituinte aos cidadãos brasileiros (BRASIL, 2012).

Desde Bresser-Pereira, a Reforma Gerencial tem tido avanços e retrocessos, mas se encontra em pleno desenvolvimento no âmbito da administração

\footnotetext{
${ }^{8}$ Incluem-se no Terceiro Setor, segundo o BNDES, organizações não governamentais, fundações e institutos empresariais, associações comunitárias, entidades assistenciais e filantrópicas, assim como várias outras instituições sem fins lucrativos.
} 
pública. Foi a mais bem sucedida no plano cultural e institucional do que propriamente operacional. Trouxe novos conceitos para a administração pública e caiu no gosto da sociedade civil ${ }^{9}$. Mesmo os governos ditos de oposição que assumiram o executivo e extinguiram o MARE continuam a utilizar-se dos princípios da nova administração pública. O MARE foi fundido com o Ministério do Planejamento passando a ser chamado Ministério do Planejamento, Orçamento e Gestão (MPOG) em 1999, vinculando-se à Escola Nacional de Administração Pública (ENAP) que deu um rumo muito claro sobre o papel da formação/ qualificação dos servidores para a reforma do Estado.

O governo de FHC foi feliz no objetivo de controlar a economia e na inserção, mesmo que tímida, das principais organizações internacionais ${ }^{10} \mathrm{em}$ um novo cenário marcado para o relacionamento (sobretudo comercial) entre as nações. No entanto, na falta de políticas sociais que efetivamente diminuíssem as disparidades entre ricos e pobres, as eleições de 2002 foram para um segundo turno, que deu a vitória ao candidato da oposição, José Inácio Lula da Silva.

No início do governo Lula da Silva, em 2003, ventilou-se que os rumos das políticas sociais caminhariam de forma a equanimizar as diferenças provenientes do capitalismo excludente. Além disso, dada a origem e a forma de criação do Partido dos Trabalhadores, a expectativa era de que, no mínimo, um debate instaurar-se-ia entre as diferentes instâncias interessadas. Entretanto, percebeu-se que, desde o início do governo Lula, o seu alinhamento continuaria " [...] com a parcela da sociedade civil que arrebanha os dotes industriais e comerciais, ou seja, a sociedade civil empresarial organizada" (LIMA, A. B. de, 2011).

Embora tenham se apresentado com alguns "ajustes", as políticas sociais do governo Lula acomodaram-se aos princípios gerenciais das leis de mercado. Não foi detectada uma ruptura política, mas uma transição gradativa, mesmo quando se instituía o debate. O número de Conselhos Consultivos cresceu 50\% no período, no entanto, a maioria deles só seriam ouvidos quando legitimavam o que o governo já queria fazer.

Observando o material disponível desde a Carta aos Brasileiros, observamos o uso de indicadores matemáticos e velhos jargões da administração empresarial, como, por exemplo, a relação eficiência-eficácia, custo-benefício, maximização de lucro-otimização de recursos, entre tantos outros. A garantia dos direitos sociais historicamente construídos não é mais uma vez, declaradamente, assumida (LIMA, A. B. de, 2011).

\footnotetext{
${ }^{9}$ Graças, sobretudo, ao trabalho midiático.

${ }^{10}$ Conforme Thomas Devort, as Organizações internacionais são associações voluntárias de Estados constituídas por meio de um Tratado, com a finalidade de buscar interesses comuns por intermédio de uma permanente cooperação entre seus membros.
} 
É com esse entendimento que passamos a tratar especificamente da Educação na qualidade de uma política de Estado (e de governos), sua reconfiguração como serviço e não como direito social, e os diversos processos de reforma conforme agenda neoliberal empreendidos nesse contexto.

\section{De direito a serviço: a questão da educação no Brasil}

Ao empreender uma busca dos documentos oficiais que regulamentam a educação no Brasil nos últimos anos, deparamo-nos com uma série deles elaborados e publicados após a Lei de Diretrizes e Bases da Educação Nacional (LDBEN) 9.394 de 1996, que caracteriza o processo de reforma empreendido em todos os níveis e modalidades da educação. A mesma LDBEN que instituiu a década da educação, que vigoraria entre 1997 e 2006, levantou as maiores expectativas e, consequentemente, inevitáveis frustrações diante das opções políticas feitas desde que seu projeto original foi engavetado e, em seu lugar, aprovado e sancionado o documento que conhecemos hoje. Todo o arcabouço legal instituído a seguir se comporia de um conjunto de instrumentos para o gerenciamento de ações que garantissem a obtenção de resultados previamente pactuados e da redefinição de toda estrutura de poder desde o Ministério da Educação até o dia a dia das instituições (SILVA; MARQUES, 2012).

A LDBEN/96 carrega, em si, a garantia de uma educação pública, gratuita e de qualidade. Assim, acreditamos que ela pode ser um importante recurso jurídico a indicar caminhos para a construção de políticas educacionais que visem à democratização do acesso, à garantia de permanência; enfim, a qualidade social do ensino praticado, principalmente, nas instituições públicas estatais.

Apesar de toda movimentação em torno das reformas, os movimentos sociais, legisladores e educadores em geral, não conseguiram cunhar um modelo de reforma que caracterizasse as bases democrático-populares difundidas nos anos de 1980 como alavanca de verdadeiras mudanças. Daí falarmos em herança desconfigurada, descaracterizada. Os ideais, as ideologias e as utopias construídas como bandeiras nos anos de 1980 foram ressignificadas nos anos de 1990, implementando-se modelos de políticas que mais sofreram continuidade na primeira década do século XXI do que alterações. (LIMA; FREITAS, 2013, p. 8).

Realizando o percurso desde a concepção da LDB até os últimos anos de vigência do Plano Nacional da Educação (PNE) 2001-2011, seria compreensível que se entendesse, a partir de sua história, que é preciso construir um projeto diferente, que converse mais efetivamente com a sociedade e represente as múltiplas vozes que nela se inscreve. Os grupos aos quais essas políticas dirigem-se, muitas vezes, não são ouvidos e, talvez por isso, não signifiquem reais mudanças 
no que se refere à integração e à justiça social. Muito menos articulam acesso, permanência e qualidade de ensino para a maioria da população. Vale destacar, aqui, uma assertiva de Florestan Fernandes sobre "o desafio educacional":

A lei, se a sociedade civil se civiliza e se democratiza, tem por fim concorrer para a extinção do servilismo, dos privilégios e do clientelismo bárbaro, que não reconhece nem respeita limites. Até o voto se converteu, em muitos lugares, em mercadoria! O "dono" do poder compra o voto e com ele elabora a democracia à sua imagem. (FERNANDES, 1989, p. 24).

Para além das heranças do nosso passado colonial, do autoritarismo em tempos de ditadura e dos cerceamentos que historicamente teceram os processos de luta pela construção democrática do Brasil e deixaram marcas profundas na nossa maneira de fazer (e não fazer) política no País, deparamo-nos, na atualidade, com novas configurações do mundo globalizado. Novos imperativos das políticas neoliberais fazem-se presentes e moldam a constituição da sociedade contemporânea, contornam o "fazer-se" político das instituições, especificamente as educacionais, sobretudo públicas e estatais (LIMA, A. B. de, 2004).

Em 1998, foi produzido pela UNESCO (1999) o documento Políticas de mudança e desenvolvimento para o ensino superior que propôs, aos países em desenvolvimento, que tanto o Estado quanto a sociedade deveriam conceber o ensino superior: "[...] menos como um peso no orçamento público e mais como um investimento nacional em longo prazo para melhorar a competitividade econômica, o desenvolvimento cultural e a coesão social" (UNESCO, 1999, p. 15).

No seio da discussão mundial sobre Educação Superior, são muitos os embates pelo modelo de Educação, Ensino e Universidade. Na qualidade de instituição, a universidade tem sido alvo de muitas críticas em todo o mundo. Ela vem sendo duramente identificada como uma organização que precisaria adaptar-se ao novo contexto de economia global. Palavras-chave abstraídas do dicionário econômico como qualidade e excelência têm sido empregadas. Termos estes que tomados isoladamente significam coisas bastante distintas a depender de onde e como são empregados (LIMA; FREITAS, 2013). O Processo de Bolonha ${ }^{11}$, em pleno processo de implantação na União Europeia, pode ser considerado um exemplo desse imperativo.

Como tentativas locais, no Brasil, algumas instituições têm tentado implantar um currículo mais flexível de modo a romper com a hierarquização dos conhecimentos. Esse novo modelo entraria em conflito com um papel que lhe

\footnotetext{
${ }^{11}$ O Processo de Bolonha é um movimento que nasceu com a Declaração de Bolonha em 1999 visando um sistema europeu de acreditação dos títulos no âmbito da União Europeia. Foi firmado com os países membros visando enfrentar a crise da educação superior europeia que se encontrava à esteira de projetos de Universidades dos Estados Unidos e Japão, considerados centro de Excelência no cenário mundial.
} 
tem sido delegado: preparação de mão de obra qualificada para o mercado de trabalho. Segundo críticas a esse movimento, toma-se que existe um risco de tratar-se de uma mudança no âmbito tecnocrático e mercantilista para as funções da universidade e não um efeito que vise afrontar os graves problemas sociais no mundo (PÉREZ, 2009).

Para Silva Júnior e Sguissardi (1999), as políticas públicas empreendidas no país, e mesmo no exterior, passam por um processo de mercadorização do espaço estatal, sob o impacto de teorias gerenciais próprias das empresas capitalistas imersas na suposta anarquia do mercado, hoje estruturado por organismos multilaterais que agem em toda a extensão do planeta. Basta retomar as bases dos novos conceitos em administração pública em que a educação, principalmente a superior, vem a ser inserida no setor de serviços não exclusivos do Estado. Para a Organização Mundial do Comércio $(\mathrm{OMC})^{12}$, o produto educação é um serviço prestado à sociedade e, mesmo que público, pode ser oferecido por diferentes instâncias. Essa perspectiva é referendada pelas demais organizações que tratam do assunto e cada Estado-membro (ou que pretende ser membro) vêm assumindo essa lógica.

A educação formal curva-se a esse modelo e, desde os anos 90, tem reorganizado o ensino, o currículo e a estrutura administrativa das instituições. A participação mais ativa na vida institucional foi intensificada não no sentido de garantir vez e voz nas principais decisões, mas referendar definições previamente pactuadas com a esfera administrativa central e suprir as deficiências de atuação estatal na manutenção e custeio, força de trabalho e avaliação/supervisão dos trabalhadores. Conforme destaca Lima, A. B. de (2010, 2011), a tomada de decisões no âmbito escolar (na perspectiva do controle social) foi levada a debate. No entanto, esse debate não tratou de conteúdos estruturantes do papel da escola, da educação, ou de gestão de recursos, mas de um conteúdo complementar, mais voltado à questão de metodologias e uma forma precisa de imputar à comunidade a responsabilidade e as garantias que deveriam ser do Estado.

Esgota-se, então, o compromisso ético-político com a classe trabalhadora. O capital requisita a eliminação dos serviços sociais executados pelo Estado, tendo em vista ser um novo campo a ser explorado pelo capital. O capital precisa eliminar o controle severo do arcabouço legal do Estado de modo a ampliar sua capacidade de acumulação e extração da mais valia. O que se inscreve teoricamente como a mundialização do capital não anula a existência dos Estados nacionais, nem as relações políticas de dominação e de dependência entre eles, mas acentua os fatores de hierarquização entre países e regiões, ampliando o abismo que

\footnotetext{
${ }^{12}$ A OMC é uma organização entre 151 países que pretende liberalizar o comércio mundial e para isso gerencia os acordos que compõe o sistema multilateral de comércio, via acordos internacionais, supervisionando o cumprimento desses acordos de modo a solucionar os possíveis conflitos entre os países membros.
} 
separa os países centrais daqueles chamados periféricos (BRAVERMAN, 1987; RUMMERT, 2000; JAMESON, 2001; OLIVEIRA, 1998; LIMA, K., 2007).

O fato é que surgem novas formas de exploração do trabalho por mecanismos subjetivos. A violência explícita de extração da força de trabalho é substituída pela tão nociva extensão da vida para o trabalho e, assim, percebe-se a contradição do trabalho escravo e as modernas tecnologias de informação e comunicação. Eis que surge o paradigma de diminuição da vida no trabalho, mas que, pelo contrário, significa materialmente a ampliação da vida no trabalho. Essa seria mais uma das estratégias contemporâneas para a redução do trabalho vivo e ampliação do desemprego estrutural (ANTUNES, 2000, 2005, 2011).

$\mathrm{Na}$ análise de Silva Júnior e Sguissardi (1999), trata-se de

[...] um processo de readequação do Estado brasileiro aos desígnios do capitalismo internacional, dado o caos econômico em que o país se encontrava e a necessidade de contornar e desfazer os preceitos da constituição federal, o desmonte da constituição foi feito de medidas provisórias, o que demonstra a subordinação do legislativo e judiciário ao poder executivo. Essas medidas foram tomadas afins [sic] de uma consolidação do acerto fiscal do Estado que se deu da negociação dívida externa e venda do patrimônio público. (SILVA JUNIOR; SGUISSARDI, 1999, p. 29).

Daí emerge a verdadeira contradição desse discurso, pois, ao mesmo tempo em que imprime a ideia de perda de centralidade do trabalho, responsabiliza o indivíduo pela intensa busca de qualificação para o trabalho, a sua empregabilidade (outra forma de nomear que está à margem da classe trabalhadora). Conforme Lima, K. (2007), torna-se fundamental

[...] para desvendar a aparência, a imediaticidade deste fenômeno e a apreender as contradições e os projetos de dominação que constituem sua essência, a compreensão da forma-conteúdo da configuração do espaço, da técnica e do tempo, conceitos-chave para análise destas duas noções cruciais da ideologia burguesa: globalização econômica e sociedade da informação. (LIMA, K., 2007, p. 38).

Não se pode considerar esse processo independentemente dos demais processos de mudanças sócio-políticas nos contextos nacional e internacional, ambos passando por grandes turbulências. Daí, podemos abstrair o conceito de desenvolvimento desigual e combinado (atraso e modernidade), conforme propôs Leon Trotsky (apud Novack, 1988), como contribuição à teoria marxista, o qual pode ser usado para descrever nações como o Brasil.

A lei do desenvolvimento desigual e combinado é uma lei científica da mais ampla aplicação no processo histórico. Tem um caráter dual ou, melhor dizendo, é uma fusão de duas leis intimamente relacionadas. O seu primeiro 
aspecto se refere às distintas proporções no crescimento da vida social. O segundo, à correlação concreta destes fatores desigualmente desenvolvidos no processo histórico. (NOVACK, 1988, p. 9).

Para explicar o que Marx entendeu como mudanças na organização do trabalho e na distribuição de mercadorias, Trotsky adota a categoria de totalidade, ou seja, liga os diferentes países pelo seu modo de produção e o seu comércio: pelo capitalismo. Ao contrário da teoria evolucionista, é esboçada uma visão dialética do desenvolvimento histórico que pode explicar a natureza capitalista dependente da colonização na América Latina. A trajetória do desenvolvimento das nações nunca é igual, nem na forma, muito menos no conteúdo. Nos países periféricos, dialeticamente a desigualdade gera o movimento, e este a modificação, a transformação e o desenvolvimento. Combinados geram desigualdade (NOVACK, 1988).

\section{A Educação Superior reestruturada, expandida, reinventada}

As instituições de Educação Superior, de maneira geral, têm procurado reestruturar-se em conformidade com as políticas públicas de educação e, consequentemente, se transformam no que Chauí (1999b, 2003a), a partir de seus estudos, identificou como "universidade organizacional"13.

A partir de um vigoroso aparato legal que justificasse o investimento público no ensino fundamental e progressivo atendimento universal à educação básica, o governo de então legitimou a rede privada a investir no projeto de expansão de Educação Superior. Esse produto - vendido como passaporte de superação de suas limitações -, e o desemprego estrutural tomam forma de falta de força de trabalho qualificada e, portanto, capaz de alcançar a tão falada empregabilidade. O mundo polariza-se entre aqueles que criam enquanto outros devem ser "treinados" para absorver as novas tecnologias (ANTUNES, 2011). "Enfim, acentua-se a nova identidade da educação superior, com novos traços: neoprofissional, pragmática, competitiva, submissa, como jamais foi aos desígnios da economia e do mercado" (SILVA JUNIOR; SGUISSARDI, 2005, p. 12).

O investimento em educação é politicamente um poderoso discurso de contenção popular já que se apresenta como saída para o alívio da pobreza e realinhamento econômico para o desenvolvimento do país. Em outras palavras, ideologia que visa exclusivamente conter uma possível reação que exigisse maior equanimidade dos direitos sociais (LIMA, A. B. de, 2010, 2011).

\footnotetext{
${ }^{13}$ Regida por contratos de gestão, avaliada por índices de produtividade, calculada para ser flexível, estruturada em estratégias de eficácia organizacional, alheios à formação intelectual e ao conhecimento. (CHAUÍ, 2003a, p. 7).
} 
Sobre a questão da expansão do acesso,

[...] a educação superior passou a receber uma espécie de choque de mercado. Tal processo passou a ser categorizado de mercantilização ou de quase mercado, na medida em que o sistema de ensino superior passou a ser orientado e estruturado, basicamente, pelos sinais de mercado e pelos interesses dos empresários da área de ensino, uma vez que o governo, por meio de certas iniciativas, instituíra as condições para a regulação pelo mercado do setor, especialmente no tocante à sua expansão. (GOMES; OLIVEIRA; DOURADO, 2011, p. 153).

Para examinar as medidas tomadas pelo executivo que incidem sobre a Educação Superior, buscamos analisar os Relatórios Técnicos produzidos pelo Instituto Nacional de Estudos e Pesquisas Educacionais Anísio Teixeira (INEP) sobre o Censo da Educação Superior ${ }^{14}$. Essa análise procurou confrontar os discursos utilizados pelas equipes de governo de democratização da oferta, com os dados disponibilizados para o controle social.

Conforme trouxemos anteriormente, a Educação Superior estatal sofreu uma retração de investimentos, principalmente no governo de FHC. No campo teórico, não faltaram estudos que se preocuparam em pensar o papel da instituição de Educação Superior, sobretudo, o papel das Universidades, principalmente as estatais.

Neste momento, propomos fazer uma leitura dos dados puros, que buscam "quantificar" a oferta e a procura para a Educação Superior. Para a escolha dos documentos a serem analisados, foi verificada a sua relevância de acordo com a sua utilização (fins ou meios). Os dados do Censo são coletados anualmente pelo Inep (2012a; 2012b) e subsidiam seus relatórios técnicos, influenciando diretamente nos resultados do Conceito Preliminar de Curso (CPC) e do Índice Geral de Cursos (IGC), índices do Sistema Nacional de Avaliação da Educação Superior (Sinaes). Os dados informados e divulgados pela instituição por meio da coleta para o Censo serão tratados neste trabalho como fontes primárias.

Começamos a analisar o número de ingressantes na Educação Superior nos anos do governo de FHC (1995-2002) e, também, no governo Lula da Silva (2003-2010).

\footnotetext{
${ }^{14}$ Anualmente, o Inep realiza a coleta de dados sobre a educação superior por meio de Formulário Eletrônico disponibilizado a todas as instituições. A coleta dos dados tem como referência as diretrizes gerais previstas pelo Decreto $n^{\circ} 6.425$ de 4 de abril de 2008.
} 
Tabela 1 - Ingressantes na Educação Superior 1995-2002

\begin{tabular}{|c|c|c|c|c|c|c|c|c|}
\hline \multirow[b]{2}{*}{ Anos } & \multirow[b]{2}{*}{ Total } & \multicolumn{5}{|c|}{ Esfera Pública } & \multicolumn{2}{|c|}{ Esfera Privada } \\
\hline & & $\begin{array}{c}\text { \% Total } \\
\text { Ano }\end{array}$ & Total & Federal & Estadual & Municipal & $\begin{array}{c}\% \text { Total } \\
\text { Ano }\end{array}$ & Privada \\
\hline 1995 & 510.377 & 31,0 & 158.012 & 72.623 & 56.703 & 28.686 & 69,9 & 352.365 \\
\hline 1996 & 513.842 & 32,4 & 166.494 & 78.077 & 58.294 & 30.123 & 67,6 & 347.348 \\
\hline 1997 & 573.900 & 31,7 & 181.859 & 86.387 & 60.537 & 34.935 & 68,3 & 392.041 \\
\hline 1998 & 662.396 & 30,2 & 200.024 & 91.354 & 68.846 & 39.824 & 69,8 & 462.372 \\
\hline 1999 & 787.638 & 27,6 & 217.497 & 103.359 & 83.843 & 30.295 & 72,4 & 570.141 \\
\hline 2000 & 897.557 & 26,0 & 233.083 & 117.507 & 91.727 & 23.849 & 74 & 664.474 \\
\hline 2001 & 1.043 .308 & 24,1 & 251.239 & 125.701 & 99.214 & 26.364 & 75,9 & 792.069 \\
\hline 2002 & 1.225 .825 & 24,0 & 294.207 & 128.749 & 132.957 & 32.501 & 76 & 931.618 \\
\hline 2003 & 1.277 .187 & 21,2 & 270.797 & 123.744 & 109.312 & 37.741 & 78,8 & 1.006 .390 \\
\hline 2004 & 1.328 .116 & 22,1 & 293.910 & 127.738 & 127.139 & 39.033 & 77,9 & 1.034 .206 \\
\hline 2005 & 1.524 .295 & 21,0 & 319.533 & 129.850 & 147.838 & 41.845 & 79 & 1.204 .762 \\
\hline 2006 & 1.660 .755 & 19,9 & 330.034 & 157.712 & 130.384 & 41.938 & 80,1 & 1.330 .721 \\
\hline 2007 & 1.784 .480 & 21,1 & 376.022 & 171.076 & 165.415 & 39.531 & 78,9 & 1.408 .458 \\
\hline 2008 & 1.936 .078 & 25,3 & 490.551 & 186.280 & 268.031 & 36.240 & 74,7 & 1.445 .527 \\
\hline 2009 & 1.819 .728 & 21,7 & 394.615 & 237.499 & 127.904 & 29.212 & 78,3 & 1.425 .113 \\
\hline 2010 & 1.922 .240 & 23,1 & 443.292 & 279.811 & 135.463 & 28.018 & 76,9 & 1.478 .948 \\
\hline
\end{tabular}

Fonte: Inep (2012a).

Observamos que a abrangência da esfera privada só ampliou-se atingindo seu ápice, de acordo com o período analisado, em 2006 - ano em que 80\% dos ingressantes na Educação Superior encontravam-se em instituições privadas. Em 2001, de acordo com dados do INEP (2012b), das 1.391 IES, apenas 13\% eram públicas. Em 2005, esse número aumenta, mas a proporção de IES privadas sobe para 89\%. Já, em 2010, a porcentagem das instituições públicas em relação às privadas continua muito baixa, sendo de $11,7 \%$.

Em relação às Matrículas na Educação Superior os relatórios trazem:

Tabela 2 - Matrículas Na Educação Superior

\begin{tabular}{l|c|c|c|c|c|c|c|c}
\hline \multirow{2}{*}{ Ano } & Total & \multicolumn{6}{|c|}{ Pública } & \multicolumn{2}{c}{ Privada } \\
\cline { 3 - 9 } & & $\mathbf{9}$ & Total & Federal & Estadual & Municipal & $\mathbf{\%}$ & Total \\
\hline $\mathbf{2 0 0 1}$ & 3.036 .113 & $\mathbf{3 1 , 1}$ & 944.584 & 504.797 & 360.537 & 79.250 & $\mathbf{6 8 , 8 9}$ & 2.091 .529 \\
\hline $\mathbf{2 0 0 2}$ & 3.520 .627 & $\mathbf{3 0 , 8}$ & 1.085 .977 & 543.598 & 437.927 & 104.452 & $\mathbf{6 9 , 1 5}$ & 2.434 .650 \\
\hline $\mathbf{2 0 0 3}$ & 3.936 .933 & $\mathbf{2 9 , 9}$ & 1.176 .174 & 583.633 & 465.978 & 126.563 & $\mathbf{7 0 , 1 2}$ & 2.760 .759 \\
\hline $\mathbf{2 0 0 4}$ & 4.223 .344 & $\mathbf{2 8 , 8}$ & 1.214 .317 & 592.705 & 489.529 & 132.083 & $\mathbf{7 1 , 2 5}$ & 3.009 .027 \\
\hline
\end{tabular}


conclusão

\begin{tabular}{c|c|c|c|c|c|c|c|c}
\hline Ano & Total & \multicolumn{6}{|c|}{ Pública } & \multicolumn{2}{c}{ Privada } \\
\cline { 3 - 9 } & & $\mathbf{\%}$ & Total & Federal & Estadual & Municipal & $\mathbf{\%}$ & Total \\
\hline $\mathbf{2 0 0 5}$ & 4.567 .798 & $\mathbf{2 7 , 3}$ & 1.246 .704 & 595.327 & 514.726 & 136.651 & $\mathbf{7 2 , 7 1}$ & 3.321 .094 \\
\hline $\mathbf{2 0 0 6}$ & 4.883 .852 & $\mathbf{2 5 , 6}$ & 1.251 .365 & 607.180 & 502.826 & 141.359 & $\mathbf{7 4 , 3 8}$ & 3.632 .487 \\
\hline $\mathbf{2 0 0 7}$ & 5.250 .147 & $\mathbf{2 5 , 4}$ & 1.335 .177 & 641.094 & 550.089 & 143.994 & $\mathbf{7 4 , 5 7}$ & 3.914 .970 \\
\hline $\mathbf{2 0 0 8}$ & 5.808 .017 & $\mathbf{2 6 , 7}$ & 1.552 .953 & 698.319 & 710.175 & 144.459 & $\mathbf{7 3 , 2 6}$ & 4.255 .064 \\
\hline $\mathbf{2 0 0 9}$ & 5.954 .021 & $\mathbf{2 5 , 6}$ & 1.523 .864 & 839.397 & 566.204 & 118.263 & $\mathbf{7 4 , 4 1}$ & 4.430 .157 \\
\hline $\mathbf{2 0 1 0}$ & 6.379 .299 & $\mathbf{2 5 , 8}$ & 1.643 .298 & 601.112 & 601.112 & 103.530 & $\mathbf{7 4 , 2 4}$ & 4.736 .001 \\
\hline
\end{tabular}

Fonte: Inep (2012a).

Relacionando o número de ingressantes e concluintes, temos:

Tabela 3 - Relação Ingressantes e Concluintes

\begin{tabular}{c|c|c|c|c|c|c|c|c|c}
\hline Ano & \multicolumn{3}{|c|}{ Totais } & \multicolumn{3}{c|}{ Sistema Público } & \multicolumn{3}{c}{ Sistema Privado } \\
\hline & Ingr. & Conc. & $\%$ Conc. & Ingr. & Conc. & $\%$ Conc/ & Ingr. & Conc. & $\%$ Conc/ \\
\hline 2001 & 1.043 .308 & 396.119 & 37,97 & 251.239 & 132.747 & 52,8 & 792.069 & 263.372 & 33,3 \\
\hline 2002 & 1.225 .825 & 467.972 & 38,18 & 294.207 & 152.813 & 51,9 & 931.618 & 315.159 & 33,8 \\
\hline 2003 & 1.277 .187 & 532.228 & 41,67 & 270.797 & 173.141 & 63,9 & 1.006 .390 & 359.087 & 35,7 \\
\hline 2004 & 1.328 .116 & 633.363 & 47,69 & 293.910 & 209.008 & 71,1 & 1.034 .206 & 424.355 & 41,0 \\
\hline 2005 & 1.524 .295 & 730.484 & 47,92 & 319.533 & 203.689 & 63,7 & 1.204 .762 & 526.795 & 43,7 \\
\hline 2006 & 1.660 .755 & 762.633 & 45,92 & 330.034 & 195.231 & 59,2 & 1.330 .721 & 567.402 & 42,6 \\
\hline 2007 & 1.784 .480 & 786.611 & 44,08 & 376.022 & 197.040 & 52,4 & 1.408 .458 & 589.571 & 41,9 \\
\hline 2008 & 1.936 .078 & 870.386 & 44,96 & 490.551 & 195.933 & 39,9 & 1.445 .527 & 674.453 & 46,7 \\
\hline 2009 & 1.819 .728 & 959.197 & 52,71 & 394.615 & 206.877 & 52,4 & 1.425 .113 & 752.320 & 52,8 \\
\hline 2010 & 1.922 .240 & 973.839 & 50,66 & 443.292 & 190.597 & 43,0 & 1.478 .948 & 783.242 & 53,0 \\
\hline
\end{tabular}

Fonte: Inep (2012a).

Conforme podemos verificar, nas tabelas 2 e 3, apesar de as matrículas nas instituições privadas serem de 2 milhões de alunos em 2001, o número de concluintes é pouco mais de 10\%. O índice é um pouco melhor nas instituições públicas, já que, das 944 mil matrículas, quase 133 mil seriam concluintes neste mesmo ano. Em 2010, comparamos esse mesmo item: das quase 5 milhões de matrículas, no ensino privado, seriam quase 800 mil concluintes, ou seja, 17\%. Nas instituições públicas, nesse mesmo ano, foram computadas 1,64 milhões de matrículas, tendo 190 mil concluintes, perto de 11\% (INEP, 2012a).

Em relação aos recursos destinados a todas as Instituições Federais de Ensino Superior (IFES), em 1995, foram repassados um pouco mais de $16 \mathrm{mi}-$ lhões de reais, enquanto que, em 2002, esse valor ficou em 12 milhões e 63 mil 
reais. Em 2005, dois anos após o ingresso de Lula da Silva à Presidência da República, esse valor já estava em 29\% negativos em relação a 1995 (SGUISSARDI; SILVA JUNIOR, 2009).

Outra informação apreendida nesses documentos é a relacionada ao número de docentes por instituição. De 2005 para 2010, o número de funções docentes em instituições federais passou de 48.539 para 78.608 - um crescimento de mais de $60 \%$. No entanto, na mesma categoria administrativa, o alunado cresceu de 595.327 para 938.656. Número este que representa, segundo o INEP (2012a), uma involução de 16,6\% para 14,7\% em relação ao número de matriculados na Educação Superior de maneira geral, ou seja, há mais alunos para menos professores.

No final do primeiro mandato, observa-se uma sensível melhora nas condições de custeio e investimento. Tendo em vista a concorrência para o segundo mandato, em 2006, o governo Lula da Silva publicou o documento Expansão das Universidades Federais: o sonho se torna realidade!, apresentado pelo então Secretário da Educação Superior Nelson Maculan Filho. O documento em forma de livro, enviado a todas as IFES, traz como objetivo apresentar o Programa Expansão, iniciado em 2003, e lançar a fase 3 de seu plano de expansão de modo "a ampliar o acesso à universidade, promover a inclusão social e reduzir as desigualdades regionais" com a meta de implantar 10 universidades e 49 campi universitários (BRASIL, 2006, p. VI).

O Programa de Apoio a Planos de Reestruturação e Expansão das Universidades Federais (REUNI) foi lançado pelo governo federal em 2007 com o objetivo de ampliar o acesso e a permanência na educação superior. Instituído pelo Decreto no 6.094/2007 (BRASIL, 2007a), o documento apresenta-se como uma série de medidas para retomar o crescimento do ensino superior público expandindo física, acadêmica e pedagogicamente a rede federal.

Demonstrando forte caráter de formação de conceitos na população, o governo federal empenhou-se na tarefa de dar ampla divulgação ao Programa. $\mathrm{Na}$ mídia em geral, sobretudo na TV, as informações davam conta de uma verdadeira revolução em matéria de educação superior no Brasil.

A evolução das despesas com manutenção e o desenvolvimento do ensino, segundo a Secretaria do Tesouro Nacional (STN), saltou de 24,4 bilhões, em 2000, para 47,4, em 2008. Especificamente na Educação Superior, no ano de 2000 , foram investidos menos que nove milhões e, em 2008, a cifra passou para 11,4 milhões.

É preciso ressaltar, no entanto, que essa sensível melhora é percebida ao ser comparada com os investimentos (ou não) do seu antecessor, mas concordamos que está aquém das necessidades e das possibilidades de realização. Conforme destaca Pinto (2009), houve um aumento real das despesas do governo federal 
com a educação, mas esse aumento decorreu mais do crescimento do Produto Interno Bruto (PIB) do que de uma maior priorização da educação, por isso ainda é insignificante. Além disso, o autor preocupa-se ao perceber que o ritmo do crescimento das despesas não está proporcional às metas fixadas de expansão. Por fim, Pinto (2009) afirma que houve uma queda relativa da participação das despesas com ensino superior e, em contrapartida, um maior comprometimento do MEC com a educação básica, embora ainda tímido.

São muitas inferências que os dados oficiais oportunizam. A contrarreforma universitária é parte ativa e componente da segunda geração de reformas estruturais, que, entre outros objetivos, pretendia naturalizar o investimento público em instituições privadas via Prouni ${ }^{15}$, diversificar as fontes de financiamento, constituir um fundo setorial de incentivo à pesquisa nas instituições privadas, e, sobretudo, diversificar as IES, diferenciando o papel das universidades das demais instituições de Educação Superior, mesmo que fosse tema de crítica quando essa equipe fazia oposição à FHC.

O REUNI pode ser visto como a materialização das orientações dos organismos internacionais para a educação pública brasileira, pois, em diversos trechos do programa, é visível a crítica ao modelo tradicional de universidade. Como, por exemplo, ajuste da legislação educacional no sentido da desregulamentação dos métodos de gestão e das instituições educacionais, garantido ao governo central maior controle e poder de intervenção sobre os níveis de ensino, via sistemas nacionais de avaliação e fixação de parâmetros curriculares nacionais, mas sem que ele mesmo participe diretamente da execução de tais serviços.

Para o ANDES-SN (2004), o REUNI é visto como uma ação coercitiva que visa redesenhar completamente a função das universidades federais, sob pretexto de aumentar suas verbas em até $20 \%$ para as instituições que se comprometem com a ampliação de $100 \%$ das vagas e a diminuição do custo/aluno da graduação.

Segundo o Relatório do primeiro ano de implantação do REUNI (BRASIL, 2009), o Programa contou com investimento de $R \$ 415$ milhões, o que permitiu a criação de aproximadamente 15 mil novas vagas de ingresso em apenas um ano, totalizando 147.277 vagas e 180 novos cursos de graduação - além de novas 1.821 vagas para docentes e 1.638 vagas aos cargos de técnicos administrativos. O documento ainda inscreve que a Pós-graduação também foi impulsionada com a concessão das Bolsas REUNI: 941 bolsas, sendo 645 de mestrado e 296 de doutorado. O documento explica que o projeto de expansão da educação superior teve duas fases: Expansão Fase 1 e o REUNI em 2007. Juntos, os dois

\footnotetext{
${ }^{15}$ O Programa Universidade para Todos (PROUNI) é, neste trabalho, entendido como um exemplo fiel da transferência dos recursos públicos, por meio de largas isenções de impostos, às universidades particulares.
} 
programas totalizam um investimento de 1,5 bilhão para a ampliação do número de cursos e vagas nas universidades federais.

Conforme dados informados no próprio sítio do REUNI, o Documento Apresentação da Expansão da Rede Federal, divulgado em 2011, apresenta dados de 2003 a 2010 e uma previsão para 2011 a 2014. O documento explica que o objetivo da expansão da Rede Federal visa atender a três dimensões: social, geográfica e de desenvolvimento. Como os dados referem-se à expansão tanto de Universidades como também de Institutos Federais, não é possível abstrair os números do REUNI especificadamente.

Iniciando com os números de institutos, o documento informa que, de 1909 a 2002, havia, no Brasil, um total de 140 campi atendendo a 120 municípios. De 2003 a 2010, esse número subiu para 354 campi em 321 municípios atendidos; e, para 2011 a 2014, pretende-se alcançar 562 campi para 512 municípios atendidos.

Em relação às universidades, primeiro é mostrado um gráfico de vagas por 10 mil habitantes e, novamente, os números, de 1808 a 2002, afirmam existir 148 campi para 114 municípios atendidos; de 2003 a 2010, 274 campi para 230 municípios atendidos; e há a previsão de 2011-2014 para uma ampliação de 321 campi para 275 municípios atendidos.

Os documentos oficiais sobre a Educação Superior permitem inferir que o destaque sai do Programa REUNI (como expansão de vagas nas Universidades Federais) para destacar os anos do governo Lula: 2003-2010 e talvez indicar que a gestão de Dilma Roussef pretende dar continuidade no Programa publicado em 2008 em forma de livro O Plano de Desenvolvimento da Educação: razões, princípios e programas (BRASIL, 2008), lançado pelo então ministro Haddad do governo de Lula, mas o foco não seria mais a Educação Universitária, e sim aquela oferecida também nos Institutos Federais de Educação Técnica e Tecnológica. Para o novo governo, a expansão dos institutos e das universidades segue o mesmo critério, ou seja, não são instituições tratadas de maneira distinta como deveriam ser seguindo o papel desempenhado por cada uma delas.

O sítio, conforme apresentado pelo Palácio do Planalto sobre o REUNI (http://reuni.mec.gov.br), foi alimentado, pela última vez, em 25 de março de 2010. Nesse endereço, é possível encontrar várias informações sobre o Programa, mas os documentos não tem uma lógica sequencial. De acordo com os documentos disponíveis, foram feitos 8 Seminários Nacionais do REUNI, mas só estão disponíveis no sítio os documentos elaborados no VI, VII e VIII. Ou seja, não temos material sobre os primeiros eventos e nem mesmo um relatório/seminário de encerramento do REUNI que, conforme Projeto, seria em 2012. 
Conforme as Diretrizes do REUNI (BRASIL, 2007b), os planos seriam acompanhados de perto pelo MEC no sentido de controlar se as metas estariam sendo de fato cumpridas. Foram disponibilizados às instituições relatórios de acompanhamento, cujas metas seriam quantificadas em porcentagem de cumprimento e justificativas seriam dadas em caso de descumprimento. Os dados desses documentos subsidiaram o Relatório de Acompanhamento do Primeiro ano do REUNI (BRASIL, 2009). Nenhum outro relatório foi produzido e divulgado.

O governo Dilma Roussef iniciou seu mandato em 2011 com uma série de medidas de contenção de orçamentos, já previstos no ano anterior, suspendendo, inclusive, concursos e novas contratações por tempo indeterminado. Para as instituições em processo de expansão, com alunos ingressando, conforme previsto no Plano de pactuação, esse endurecimento do executivo foi um caos.

Pressionado pela Associação Nacional dos Dirigentes das Instituições Federais de Ensino Superior (ANDIFES), o governo flexibilizou a situação criando, provisoriamente, uma nova categoria funcional de prestadores de serviços de docência: os temporários. As vagas pactuadas para a carreira efetiva do magistério superior foram transformadas em contratos temporários de 6 meses, prorrogados por até 2 anos.

Em relação aos técnicos administrativos, na visão do executivo, novas contratações poderiam esperar. As IFES tiveram seu quadro de terceirizados ampliado e foi possível constatar que, além dos serviços de limpeza e vigilância, agora o espaço administrativo também contava com essa nova categoria de força de trabalho.

Esse foi o contexto que eclodiu na deflagração de greve geral nas IFES a partir de 17 de maio pela Associação Nacional dos Docentes de Instituições de Educação Superior - ANDES-SN. Segundo esse sindicato, a pauta da Campanha 2012 seria a reestruturação da carreira - prevista no Acordo firmado em 2011 e descumprido pelo governo federal.

Inicialmente, a greve teve adesão de 29 instituições. Um mês após, já seriam 55 instituições no movimento de um total de 44 universidades federais e 55 institutos ou escolas isoladas. Segundo matéria difundida em um dos maiores veículos de comunicação impressa em forma de revista semanal publicada em 14 de junho 2012, nas suas reivindicações, os professores alegaram que as universidades federais têm vivido um processo de "precarização", consequência da política de "expansão desordenada" iniciada pelo REUNI. Na esteira do movimento dos docentes, os funcionários técnicos administrativos começaram a sua mobilização.

Apesar de vários protestos com a mobilização de instituições de todo Brasil, o governo cancelou, inúmeras vezes, rodada de negociação com os grevistas. 
Vários tribunais jurídicos confirmam legalidade da greve apesar do endurecimento por parte do governo em abrir a mesa de negociações enquanto as aulas não fossem retomadas. Os calendários acadêmicos da maioria das instituições foram suspensos por prazo indeterminado de reuniões em seus Conselhos deliberativos.

Em 27 de junho, o balanço da ANDES-SN ${ }^{16}$ apontava que 95\% das instituições aderiram à greve. $\mathrm{O}$ Comando destaca que a força do movimento confirma-se com o apoio da sociedade, mesmo com a falta de destaque pela mídia nacional. Os debates locais ampliam-se e incorporam discussões sobre investimento do governo para a educação e a vinculação dos $10 \%$ do PIB, que, no momento, estava sendo discutido no Plano Nacional de Educação - 2011-2020.

Em uma manobra histórica, o governo retira-se das negociações e resolve assinar, no dia $1^{\circ}$ de agosto, um acordo com o Pro-IFES, uma entidade representativa de docentes de instituições federais que congrega um número ínfimo de sindicalizados e o leva para a grande mídia como um acordo feito entre movimento grevista e governo, pelo fim da greve. Com mais de 100 dias de greve, o Comando Nacional de Greve (CNG) participa de uma audiência pública no Senado Federal para debater o movimento de greve. Apesar do número alto de adesões das instituições federais, no interior destas, o movimento dá sinais de perder a sua força e grevistas começam a voltar ao trabalho. Enfim, no dia 16 de setembro, após 120 dias de greve, a maior da história, o CNG anuncia encerramento das atividades.

Conforme Lima, A. B. de (2011, p. 31), “[...] perseguir a democracia e a democratização exige, pois, não somente teorizar a sociedade, mas também, o fazer histórico [...] [pois] é na práxis que o homem deve demonstrar a verdade, isto é, a realidade e o poder, o caráter terreno de seu pensamento". A partir desse ponto de vista, é preciso concordar com o autor que precisamos aprender com os movimentos sociais como opções históricas de se fazer democracia. Movimentos estes que ora ganham, ora perdem os embates em um processo conflitual, dinâmico, um universo em construção.

Dessa forma, entendemos que o movimento que ocorreu em 2012 foi um marco na história do movimento docente e da classe trabalhadora brasileira como um todo, isso pelo que ele conseguiu criar em termos de fatos políticos e culturais. Mesmo com 33 instituições paralisadas, o governo optou por desdenhá-lo. O Ministro Aluizio Mercadante, o relator do governo, conceituou o movimento como "inoportuno".

Quando o movimento alcançou dimensões inimagináveis para ambos os lados, a estratégia do governo foi ousada. Mesmo que o movimento tenha

\footnotetext{
${ }^{16}$ A ANDES publicava em tempo real as últimas notícias da greve em seu sítio oficial: <http://www.andes.org.br >.
} 
trazido para o seu bojo o movimento estudantil independente e a união com os trabalhadores técnicos em educação, a manobra ultrajante dos representantes do governo foi descaracterizar o maior sindicato da categoria ao negociar com uma entidade de mínima representatividade. Foi assinado um acordo com o PROIFES e dadas por encerradas as negociações. Mesmo com a luta intensificada para a reabertura da mesa de negociações, o foco em algumas das reivindicações da proposta original não foi suficiente.

Do saldo do movimento de 2012, as conquistas fizeram-se mais no campo político do que de resultados. O movimento desvelou o universo mais concreto do cotidiano das práticas educativas que se materializam no dia a dia das instituições públicas de educação superior. Estas se percebem como ferramentas/instrumentos de expansão do capital - um produto mensurável como de primeira ou segunda linha, conforme determina a lei de oferta e de procura. A resistência continua e é forte, mesmo que os sindicatos não consigam grandes processos de mobilização. As estratégias do governo de plantão vão se sofisticando de modo a atingir o sujeito que não se vê mais como classe, categoria, mas um indivíduo que tem ganhos ou perdas. Nesse caso, essa foi a maior perda do movimento. A supremacia do indivíduo sobre o coletivo. Ainda assim, acreditamos no movimento histórico e no distanciamento do presente para entender o passado e o futuro.

\section{Considerações finais}

A Educação Superior tem passado por um processo crescente de reestruturação rumo ao que pode ser chamado de privatização interna e mercantilização das relações sociais e estrutura organizacional. Todos esses elementos refletem uma direção que vem sendo dada, nacionalmente, à universidade, transformando-a em organização administrativa, baseada na racionalidade técnica, contrária à dimensão social característica dessa instituição. No caso das instituições estatais, passa agora a ser "expandida" e "reestruturada", trazendo, para o seu interior, o cerne das lutas sociais. Formação para as elites nos cursos tradicionais ofertados no diurno, e, para aqueles-que-vivem-do-trabalho, cursos menos dispendiosos para a máquina pública administrativa - uma grande linha industrial com produtos de primeira e segunda linha, tendo o rendimento como finalidade e as leis do mercado como condição de permanência e sobrevivência.

Sobre esse ponto, é preciso ressaltar que o ano de 2012 contou com vários desdobramentos da Grande Greve. O movimento histórico que o Brasil atravessa, de ajustamento às leis de mercado e de concorrência entre as nações, referencia essa análise que pretende ir além dos dados quantitativos apurados. 
Ela busca as origens históricas desse movimento no sentido de compreender as relações micro e macro desse universo.

A tão sonhada democratização do acesso a um ensino público de qualidade tem se mostrado um engodo para a população de maneira geral. Os cursos menos dispendiosos, os quais atraem para uma carreira não tão valorizada, como a de professor, o número de desistentes é grande, embora o Censo da Educação Superior não mostre essa informação claramente.

É tempo, enfim, para a universidade assumir seu nome, sendo ao mesmo tempo universal e particular, constituindo uma instituição do Estado, no sentido mais amplo possível. Ela deve servir como instrumento eficaz de aquisição e invenção de saberes, transmitindo-os em larga escala ao povo. Caso contrário, ela estará apenas colaborando para a morte coletiva, calada, como os doutores silentes e cúmplices nos regimes totalitários. Não temos força física, não ordenamos as leis, não temos o controle do excedente econômico. Estas são as marcas do poder. Mas ainda possuímos autoridade científica e alguma ética. (ROMANO, 2006, p. 46).

A proposta deste artigo, longe de esgotar a temática, problematiza a Educação Superior como uma política estatal que não tem como objetivo empoderar a sociedade de uma educação verdadeiramente superior via Universidade pública, gratuita e estatal. A educação superior proposta nesse contexto, em seu discurso, promete transcender o papel de atendimento ao cenário produtivo. No entanto, na prática, acaba não atingindo a esse objetivo, muito menos àquele que lhe foi delegada socialmente: a emancipação dos sujeitos históricos.

Nessa dialética, reside o movimento ora de ajustamento, ora de enfrentamento a esta complicada realidade. Assim, no que tange às políticas públicas para a Educação Superior, estas já nascem com uma missão quase impossível de aproveitar o momento de possibilidades, mesmo que o terreno não seja tão fértil à emancipação, às rupturas com a realidade posta e o respeito às subjetividades dos sujeitos.

O Estado Democrático e de direito, que deveria ser regulado por leis e ter como alvo o bem, a verdade, a beleza em todos os aspectos da vida humana e garantir a integridade corporal e do pensamento, acaba desprovido de fé pública, tornando-se apenas uma máscara trágica ou cômica do poder baseado no direito. Para encerrar, provocamos: "Nenhum carisma, por mais encanto que possua o seu possuidor, resiste à corrosão da confiança cidadã" (ROMANO, 2006, p. 46).

\section{Referências}

ANDES-SN. A contra-reforma da Educação Superior. Uma análise do ANDES-SN das principais iniciativas do Governo de Lula da Silva. Brasília, 2004. 
ANTUNES, R. Os sentidos do trabalho. São Paulo: Boitempo, 2000.

ANTUNES, R. Adeus ao trabalho? Ensaio sobre as metamorfoses e a centralidade do mundo do trabalho. Campinas: Editora da Unicamp, 2005.

ANTUNES, R. O continente do labor. São Paulo: Boitempo, 2011.

BARROS, L. C. M. de. Os desafios da macroeconomia brasileira. In: BIELSCHOWSKY, R.; MUSSI, C. (Orgs.). Políticas para a retomada do crescimento: reflexões de economistas brasileiros. Brasília, IPEA/CEPAL, 2002. p. 107-116.

BRASIL. Ministério da Administração Federal e Reforma do Estado/Secretaria da Reforma do Estado. Organizações sociais. Brasília: Ministério da Administração e Reforma do Estado, 1997. (Cadernos MARE da reforma do estado, v. 2).

BRASIL. Ministério da Educação. Expansão das universidades federais: o sonho se torna realidade! Período de 2003 a 2006. Brasília, 2006.

BRASIL. Decreto $\mathbf{n}^{\mathbf{0}} \mathbf{6 . 0 9 4}$ de 24 de abril de 2007. Dispõe sobre a implementação do Plano no de Metas Compromisso Todos pela Educação. Brasília, 2007a.

BRASIL. REUNI - Reestruturação e Expansão das Universidades Federais: Diretrizes Gerais, Brasília, 2007b.

BRASIL. O Plano de Desenvolvimento da Educação: razões, princípios e programas. Ministério da Educação, Brasília, 2008.

BRASIL. Ministério da Educação. Secretaria de Educação Superior. Reuni 2008 - Relatório de Primeiro Ano. Brasília, 2009.

BRASIL. Ministério do Planejamento, Orçamento e Gestão. Instituto Brasileiro de Geografia e Estatística (IBGE). As Fundações Privadas e sem fins lucrativos no Brasil. Rio de Janeiro, 2012. Disponível em: <ftp://ftp.ibge.gov.br/Fundacoes_Privadas_e_Associacoes/2010/ fasfil.pdf $>$. Acesso em: 5 set. 2013.

BRAVERMAN, H. Trabalho e capital monopolista: a degradação do trabalho no século XX. Rio de Janeiro: Guanabara, 1987.

BRESSER-PEREIRA, L. C. Do Estado patrimonial ao gerencial. In: SACHS, I.; WILHEIM, J.; PINHEIRO, P. S. de M. S. (Orgs.). Brasil: um século de transformações. São Paulo: Cia. das Letras, 2001. p. 222-259.

BRESSER-PEREIRA, L. C. Desenvolvimento e crise no Brasil: história, economia e política de Vargas a Lula. 5. ed. São Paulo: 34, 2003.

BRESSER-PEREIRA, L. C. Brasil, Sociedade Nacional-Dependentes. Novos Estudos CEBRAP, São Paulo, n. 93, p. 101-121, jul. 2012.

CHAUÍ, M. A universidade operacional. Revista Adunicamp - desafios da universidade pública, Campinas, v. 01, n. 01, p. 06-09, jun. 1999a.

CHAUÍ, M. Reforma do Ensino Superior e autonomia universitária. Serviço Social e Sociedade, São Paulo, v. 61, p. 118-126, 1999b.

CHAUÍ, M. Escritos sobre a universidade. São Paulo: Editora da UNESP, 2001.

CHAUÍ, M. A universidade pública sob nova perspectiva. Revista Brasileira de Educação, Rio de Janeiro, n. 24, set./dez. 2003a. DOI: 10.1590/S1413-24782003000300002 
CHAUÍ, M. Cultura e democracia: o discurso competente e outras falas. 10. ed. São Paulo: Cortez, 2003b.

DOURADO, L. F.; CATANI, A. M.; OLIVEIRA, J. F. A política de avaliação da educação superior no Brasil em questão. In: SOBRINHO, J. D.; RISTOFF, D. I. (Orgs.). Avaliação Democrática Para uma Universidade Cidadã. Florianopólis, SC: INSULAR, 2002. v. 1. p. 99-118.

FERNANDES, F. O desafio educacional. São Paulo: Cortez e Autores Associados, 1989.

FERRAREZI, E. Legados da professora Ruth Cardoso ao governo federal. Revista do Serviço Público, Brasília, v. 59, n. 2, p. 237-244, abr./jun. 2008.

FRANÇA, P. I. S. de. As reformas no setor educacional brasileiro e a expansão da Educação Superior. In: FRANÇA, R. L. (Orgs.). Educação e trabalho: políticas públicas e a formação para o trabalho. Campinas: Alínea, 2010, p. 89-110.

GENTILI, P. A falsificação do consenso: simulacro e imposição na reforma educacional do neoliberalismo. Petrópolis, RJ: Vozes, 1998.

GOMES, A. M.; OLIVEIRA, J. F. de; DOURADO, L. F. Políticas de Educação Superior no Brasil: mudanças e continuidades. In: PAULA, M. de F. C. de.; LAMARRA, N. F. (Orgs.). Reformas e democratização da Educação Superior: no Brasil e na América Latina. Aparecida - SP: Idéias Letras, 2011, p.153-190.

INEP. Instituto de Estudos e Pesquisas Anísio Teixeira. Relatórios Técnicos do Censo da Educação Superior, 2001-2010. Brasília, 2012a.

INEP. Censo da Educação Superior 1995-2011. Brasília: INEP. 2012. Disponível em: <http://portal.inep.gov.br/superior-censosuperior-sinopse>. Acesso em: 18 nov. 2012b.

JAMESON, F. A cultura do dinheiro: ensaios sobre a globalização. Petrópolis: Vozes, 2001. LIMA, A. B. de. Estado, políticas educacionais e gestão compartilhada. São Paulo: Xamã, 2004.

LIMA, A. B. de. Estado, educação e controle social. In: FRANÇA, R. L. de. Educação e trabalho: políticas públicas e a formação para o trabalho. Campinas: Alínea, 2010. p. 11-30.

LIMA, A. B. de. Estado e controle social no Brasil. Uberlândia: EDUFU, 2011.

LIMA, A. B.; FREITAS, D. N. T. de. Políticas sociais e educacionais: cenários e gestão. Uberlândia - MG: EduUfu, 2013.

LIMA, I. R. S. Mundialização e trabalho precário: não espantem o mercado ou quanto vale a sua mão? Revista Espaço Acadêmico, Maringá, v. 63, p. 1-4, 2006.

LIMA, K. Contra-reforma na educação superior: de FHC a Lula. São Paulo: Xamã, 2007.

NOVACK, G. Desenvolvimento desigual e combinado da sociedade. Rabisco, 1988.

OLIVEIRA, F. de. Os direitos do antivalor: a economia política da hegemonia imperfeita. Petrópolis: Vozes, 1998.

PÉREZ, F. F. G. Puede la universidad contribuir a la mejora real de la educación? In: PINTO, J. M. R. O financiamento da educação no governo Lula. Revista Brasileira de Política e Administração da Educação, Porto Alegre, v. 25, n. 2, p. 323-340, maio/ago. 2009.

ROMANO, R. Reflexões sobre a universidade. In: SILVA, M. A. da.; SILVA, R. B. (Orgs.). A ideia de Universidade: rumos e desafios. Brasília: Líber Livro, 2006, p.17-47. 
RUMMERT, S. M. Educação e identidade dos trabalhadores: as concepções do capital e do trabalho. São Paulo: Xamã; Niterói: Intertexto, 2000.

SGUISSARDI, V. Universidade brasileira no século XXI. São Paulo: Cortez, 2009.

SGUISSARDI, V.; SILVA JÚNIOR, J. R. Trabalho intensificado nas federais: pósgraduação e produtivismo acadêmico. São Paulo: Xamã, 2009. v. 1.

SILVA JUNIOR, J. dos R. O professor pesquisador nas universidades públicas no contexto da internacionalização do capital: a produtividade do trabalho imaterial superqualificado. Revista Portuguesa de Educação, v. 22, p. 145-177, 2009.

SILVA JUNIOR, J. dos R. A mundialização da produção do valor e a racionalidade das reformas da educação. In: ALMEIDA, M. de L. P. de; PEREIRA, E. M. de A. (Org.). Políticas educacionais de Ensino Superior no século XXI: um olhar transnacional. Campinas: Mercado de Letras, 2011, v. 1, p. 21-69.

SILVA JUNIOR. J. R.; SGUISSARDI, V. Novas faces da Educação Superior no Brasil Reformas do Estado e mudanças na produção. Bragança Paulista: EDUSF, 1999.

SILVA JUNIOR. J. R.; SGUISSARDI, V. A educação superior privada no Brasil: novos traços de identidade. In: SGUISSARDI, V. (Org.). Educação Superior: novos e velhos desafios. São Paulo: Xamã, 2000a, p.155-180.

SILVA JUNIOR. J. R.; SGUISSARDI, V. A produção intelectual sobre Educação Superior na Revista Brasileira de Estudos Pedagógicos (RBEP): período 1968-1995. Revista Brasileira de Estudos Pedagógicos, Brasília, v. 79, n. 193, p. 95-112, 2000 b.

SILVA JUNIOR. J. R.; SGUISSARDI, V. O Público e o Privado na educação superior no Brasil nos anos noventa: a última reforma do século. Cadernos do IFAN, Bragança Paulista, v. 23, n. 23, p. 61-99, 2000c.

SILVA JUNIOR. J. R.; SGUISSARDI, V. A nova lei da educação superior: fortalecimento do setor público e regulação do privado/mercantil ou continuidade da privatização e mercantilização do público? Revista Brasileira de Educação, Rio de Janeiro, n. 29, p. 5-27, maio/ago. 2005. DOI: 10.1590/S1413-24782005000200002

SILVA JUNIOR. J. R.; SGUISSARDI, V. La forma y los motivos de la expansión de la Educación Superior pública en Brasil. Revista de la Educación Superior, v. 41, p. 67-86, 2012.

SILVA JUNIOR. J. R.; SGUISSARDI, V. Trabalho intensificado nas federais: pósgraduação e produtivismo acadêmico. São Paulo: Xamã, 2009, v. 1, 271p.

SILVA, M. V.; MARQUES, M. R. A. (Orgs.). LDB: Balanços e perspectivas para a educação brasileira. 2. ed. Campinas: Alínea, 2012.

UNESCO. Política de mudança e desenvolvimento no Ensino Superior. Rio de Janeiro: Garamond, 1999.

Recebido em 02/12/2013

Versão final recebida em 10/03/2014

Aceito em 17/03/2014 